\title{
Deafness, culture, and choice
}

\section{N Levy}

We should react to deaf parents who choose to have a deaf child with compassion not condemnation

$\mathrm{T}$ here has been a great deal of discus sion during the past few years of the potential biotechnology offers to us to choose to have only perfect babies, and of the implications that might have, for instance for the disabled. What few people foresaw is that these same technologies could be deliberately used to ensure that children would be born with (what most people see as) disabilities. That this is a real possibility, and not merely the thought experiment of a philosopher, is brought home to us by the decision of an American lesbian couple to select a deaf sperm donor in order to maximise the chances that their children, Jehanne and Gauvin, would be deaf like them. ${ }^{1}$ Their choice has sparked controversy, not only among medical ethicists, but in the opinion pages of newspapers across the world. Ought parents be permitted to make such choices?

If the parents of Jehanne and Gauvin have done anything wrong, it must consist in violating their child's right to an open future-limiting its future potential for choice. ${ }^{2}$ But what does it mean to respect this right?

From the moment a child is born, her parents are making choices for her, which will powerfully shape her future. They will decide what kind of education she will have, what religious experiences, from among what group she can select friends. Thereby, they profoundly mould the person she will be and the life she will have.

When this activity is carried out within certain, ill-defined, limits, it is in no way objectionable. It is not merely a contingent fact about human beings that they must be educated in one way or another, and that this education will forever shape their future selves. It is, also, a profound metaphysical fact that freedom is necessarily constrained. If we did not bring values and expectations to our choices, we would have no basis upon which to make them. Thus, what is seen from one angle as the limiting of a child's future choices is, from another angle, the constitutive condition of her having choices at all. Only from within a certain, necessarily unchosen, framework can the child begin to make something of what she has been made.

Whether a parent's decisive choices on behalf of her child amount to an infringement of her right to an open future is, therefore, difficult to deter-

\section{Culture and compassion}

The recent controversy surrounding the choice, by a deaf lesbian couple, to have children who were themselves deaf, has focused attention on the ethics of choosing (apparent) disabilities for children. Deaf activists argue that deafness is not a disability, but instead the constitutive condition of access to a rich culture. Being deaf carries disadvantages with it, but these are a product of discrimination, not of the condition itself. It is, however, implausible to think that all the disadvantages which stem from deafness are social in origin. Moreover, though it may be true that being deaf carries with it the important compensation of access to a rich culture, no physical condition is required for such access. Cultures are simply the kind of things to which we are born, and therefore to which the children of deaf parents, hearing or deaf, normally belong. Thus these parents are making a mistake in choosing deafness for their children. Given their own experience of isolation as children, however, it is a mistake which is understandable, and our reaction to them ought to be compassion, not condemnation.

mine. We have no way of marking a precise boundary, within which such choices are the necessary preconditions of the child's own decisions, and beyond which too many options are foreclosed. All we can do is try to make some sort of judgment.

Does choosing deafness overstep this imprecise boundary? Deaf activists often argue that deafness is not a disability. Instead, it is the constitutive condition of access to a rich and valuable culture. For this reason, they might claim, choosing deafness falls well within the bounds of the permissible; it is a choice which opens up as many and as valuable options as it closes down. They cannot deny that, on average, the deaf do much worse than the hearing on a range of significant indicators of quality of life: unemployment, education levels, income, and so on. But they argue that this is a consequence of discrimination against them, overt and covert, and not of deafness itself. If society were structured to allow for the full participation of the deaf, they maintain, the negative effects of deafness would be entirely eliminated. In this sense, deafness is strictly analogous to blackness; blacks, too, do worse, on average, than their white peers, but this is an artefact of discrimination, not a consequence of skin colour.

If all the disadvantages which stem from deafness were traceable to discrimination, or even if they could all be eliminated by thoughtful planning, in the manner in which we can eliminate some of the disadvantages suffered by the wheelchair-bound by designing buildings with ramps, then this claim would be vindicated. And indeed, there is a great deal we can do to eliminate such disadvantages. We can caption television broadcasts, we can provide sign interpreters, and so forth. The internet has revolutionised the lives of many of the deaf, making communication, via email, as easy for them as it has been for most of us ever since the invention of the telephone. Though much has been done, however, and a great deal more could be achieved, we can expect the deaf always to be at some disadvantage. We are, in many ways, a logocentric culture-one which is centred around the voice. The deaf will always be cut off from the buzz of conversation, always restricted to a narrower range of jobs, always slightly alienated from the mainstream of political, social, and cultural life. Deaf culture may have its compensations, but they cannot entirely make up for this estrangement.

Choosing deafness is, therefore, choosing a real (though not an especially severe) limitation. To that extent, deaf children have their future somewhat narrowed. Moreover, there is a sense in which this narrowing is uncompensated. For the children of the deaf, access to deaf culture is not the compensation they receive for their disability, it is their birthright. Culture, like language, is normally passed on without effort. Any 
baby, hearing or deaf, will pick up sign language and speak it as a first language, so long as it is exposed to it regularly. Thus, this couple did not need to make any special effort to ensure that their children would share their culture. A hearing child will pick up sign and a spoken language, just as the children of immigrants typically learn the language of their parents and the language of their adopted homeland. The hearing child of deaf parents might be said to have a maximally open future, since she participates, as a full member and not merely an onlooker, in two cultures.

The desire of parents to have their children share their culture is perfectly reasonable. It enhances empathy on both sides, enabling parents to assist their children in negotiating the road to adulthood that much more surely, and potentially increasing the satisfactions upon both sides. But deaf parents do not need to choose to exclude their children from the hearing world in order to include them in theirs; both are open to them. Though these parents might be guilty of restricting the range of their children's options to some extent, however, we ought not to be too hasty in condemning them. We ought to remember the extent to which they, like many other deaf people, felt isolated and alone as children, cut off not only from their schoolmates but also from their own family. They fear a similar fate for their children; that a nearly insuperable barrier will divide mother and child. In reality, their fear is misplaced. But it is comprehensible. Given this fact, and given the fact that the disadvantages which their children will suffer are likely to be relatively mild, we ought to react to them with compassion and understanding, not condemnation.

J Med Ethics 2002;28:284-285

Author's affiliations

N Levy, Centre for Applied Philosophy and Public Ethics, University of Melbourne, Parkville, Victoria 3010, Australia;

nllevy@unimelb.edu.au

\section{REFERENCES}

1 Mundy L. A world of their own. Washington Post 2002 Mar 31: W22.

2 On this right see Feinberg J. The child's right to an open future. In: Aiken W, LaFollette $\mathrm{H}$, eds. Whose child? Children's rights, parental authority, and state power. Totowa, NJ: Littlefield, 1980: 124-53. 